\title{
Syphilis and cirrhosis: a lethal combination in a XIX century individual identified from the Medical Schools Collection at the University of Coimbra (Portugal)
}

\author{
Célia Lopes ${ }^{1 /+}$, Mary Lucas Powell ${ }^{2}$, Ana Luísa Santos ${ }^{1}$ \\ ${ }^{1} \mathrm{CIAS}$ - Research Center for Anthropology and Health, \\ Department of Life Sciences, University of Coimbra, Coimbra, Portugal \\ ${ }^{2}$ Paleopathology Newsletter, Lexington, KY, USA
}

\begin{abstract}
Syphilis is a chronic infection that is categorized by a three-stage progression. The tertiary stage may affect bones and produce distinctive skull lesions called caries sicca. This paper aims to present an unusual case of syphilis associated with a diagnosis of cirrhosis, which was recorded as the cause of death in a 28-year-old female in 1899. The appearance and distribution of the lesions were compatible with acquired syphilis, as observed in the skull from the Medical Schools Collection of the University of Coimbra. However, the cause of death was recorded as "hypertrophic cirrhosis of the liver", this is a condition that is compatible with several liver disorders, including a primary liver disorder, such as cirrhosis provoked by alcoholism, infection of the liver by syphilis pathogens or by damage to the liver from the use of mercury compounds, which was the common treatment for syphilis at the time. This paper represents a contribution to the understanding of the natural evolution of syphilis.
\end{abstract}

Key words: syphilis - paleopathology - therapy

Acquired syphilis is an acute, subacute or chronic treponematosis characterized by development in three clinical stages (Musher 1999). The first stage is identified only by a primary lesion or chancre and the second phase features a rash that affects the skin and mucous membranes (Aufderheide \& Rodríguez-Martín 1998, Wöhrl \& Geusau 2007). In its tertiary stage, the disease can cause serious damage to virtually all parts of the human body; for example, it can lead to hepatic cirrhoses in the liver (Rebocho 1921, Peeters et al. 2005, Heidelbaugh \& Bruderly 2006). The skull is the most common location of tertiary syphilitic lesions (Ortner 2003, Powell \& Cook 2005, Marden \& Ortner 2009). These lesions, which are called caries sicca, are considered by many authors as being pathognomonic for acquired syphilis (Hackett 1976) or, more broadly, treponematosis, such as yaws or endemic syphilis (Ortner 2003). Caries sicca is the term proposed by Virchow, in 1896, to describe a specific type of skeletal lesion: "the scar which remains after superficial gummatous osteitis" (Aufderheide \& Rodríguez-Martín 1998). Later, in 1976, Hackett described the three stages of the developmental sequence of this characteristic lesion that is associated with individuals with acquired syphilis. The initial stage is characterized by clustered and confluent pits; this is followed by a discrete sequence of focal superficial cavitation, circumvallate cavitation and the formation of distinctive radial scars. The process concludes with serpiginous and nodular cavitation.

Financial support: FCT (SFRH/BD/36954/2007)

+ Corresponding author: lopesc03@gmail.com

Received 18 March 2010

Accepted 18 August 2010
In the late XIX and early XX centuries, syphilis became an increasingly epidemiological problem that was mainly due either to the failure of the official prophylactic measures or to the non-existence of effective chemotherapy. The disease became increasingly feared as more was learned about its effects on the human body; because of its association with decadence, lust and illicit sexual behavior, the disease earned the title of the "contemporary plague" (Vaquinhas 1992). The general fear of this disease is clear from Rebocho's (1921) remarks: "syphilis has been so aggravating, from generation to generation, that we can say that there are few people who can be considered free of its powerful influence". However, it is not known precisely how many people were infected in Portugal. In 1905, the true impact of the disease was confirmed and extended with the identification of Treponema pallidum by Schaudinn and Hoffman (Davidson \& Hall 2001). In 1906, the discovery of the Wasserman diagnostic test for syphilis made the identification during its latent period possible (Hall 2001).

Since the emergence of syphilis in Europe in the late XV century, various treatments have been developed. By the XIX century, mercury was the only drug that was somewhat effective in the treatment of syphilis (Quétel 1990, Hall 2001). Mercury was administered in three ways: intravenous injection, ingestion of pills and in ointments rubbed into the skin (Guimarães 1897).

The aim of this paper was to present an unusual case from 1899 that involved an identified skull, which displayed signs of acquired syphilis and "hypertrophic cirrhosis of the liver". The possible nexus of these two conditions is also discussed.

Skull number 282 belonged to an unmarried housemaid, aged 28, who was born in Chaves and died on November 27 1899, in Lisbon, where she probably lived. This case is included in the Medical Schools Collection 
housed at the University of Coimbra. The collection catalogue stated "hypertrophic cirrhosis of the liver" as the cause of her death.

For this paper, a detailed description of the bone lesions observed through macroscopic observation with a 10X magnifying hand lens was recorded and the endocranial surface was examined with a lighted probe.

The pathological changes observed on the outer surface of the cranial vault of case number 282 included lytic lesions with evidence of healing and irregular rounded margins on several bones, which were most evident on the frontal and bilateral parietal bones. On the frontal bone, the typical caries sicca lesions were present at all stages of development. Pitting was evident on the affected areas and was more advanced over the orbits (Fig. 1A, B). The
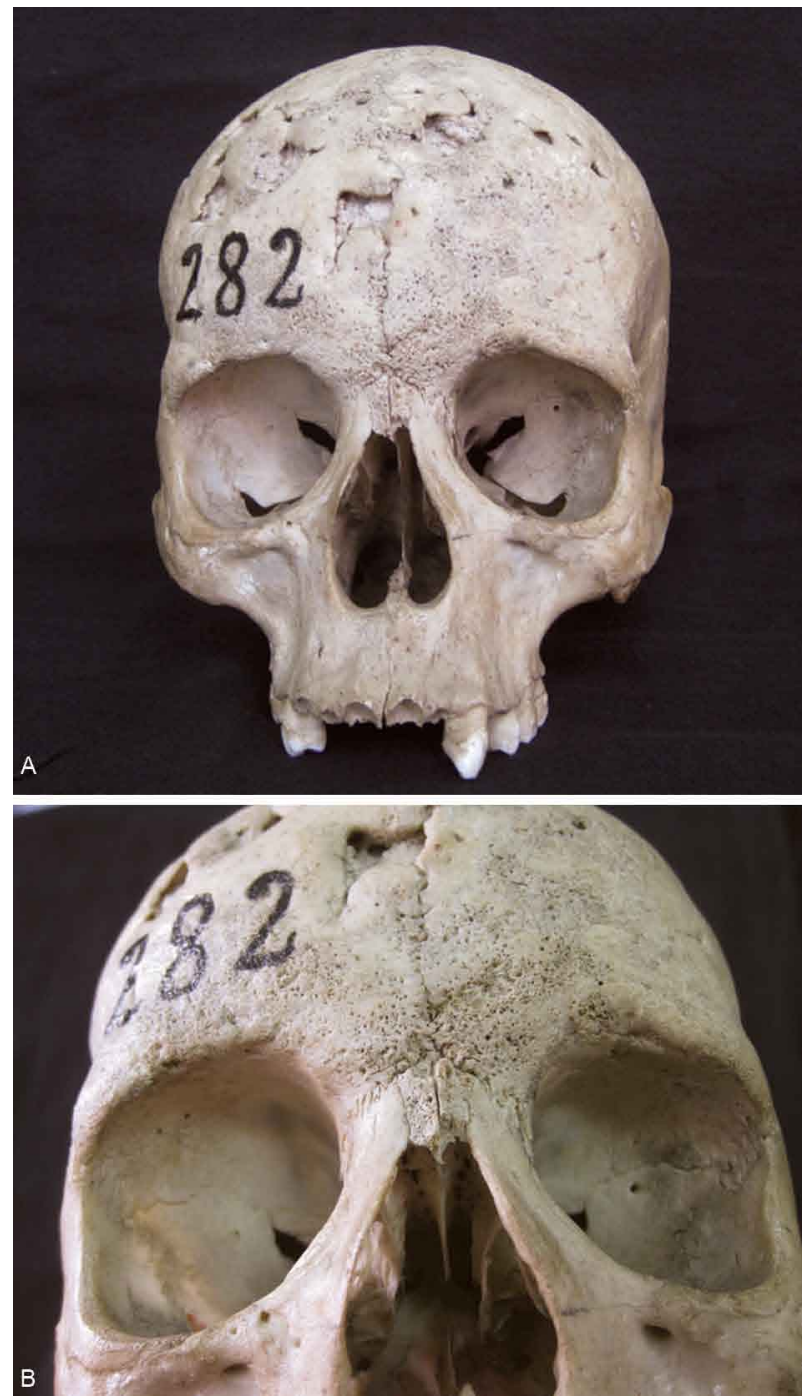

Fig. 1A: in the anterior view can be seen the destructive lesions on the frontal, surrounding the metopic suture, as well as the areas of pitting affecting the arcus superciliaris and margo supra-orbitalis regions; $\mathrm{B}$ : a thin layer of new bone deposition, smooth and remodelling, is evident on the inner surfaces of the orbits.

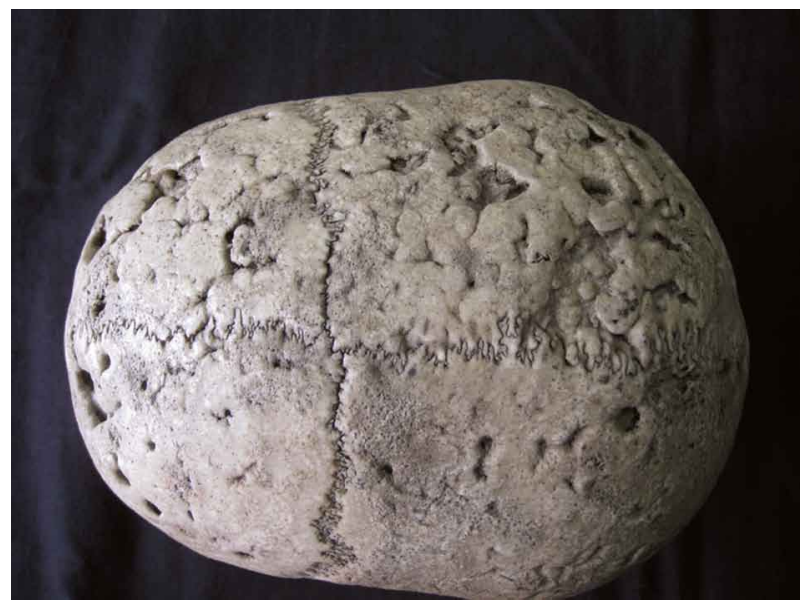

Fig. 2: the entire cranial vault is affected by caries sicca, the lesions being more severe on the right side.

superior lateral portions of the orbits were smooth and displayed remodelling of a thin layer of newly deposited bone. The left orbit was more severely affected than the right. The right side of the cranial vault was more severely affected than the left side, both in the extent and depth of the lesions (Fig. 2). The right parietal showed caries sicca in all stages, which were particularly evident around the sagittal suture and the superior portion of the vault. Below the superior temporal line, several scars were visible, but were not associated with cavitation; the same was true for the posterior aspect of the parietal bone, where porosity was clearly visible. Many of the ectocranial lesions extended into the diploë producing an irregular surface but not penetrating the inner table. The left parietal bone was significantly less affected than the right; it showed severe pitting and some radial scars but without extensive caries sicca. This bone was unaffected below the superior temporal line. Both temporal bones showed very small areas of pitting on the suprameatal and supramastoid crests. The occipital bone was almost unaffected, except for one small area of pitting on the left side, posterior to the middle of the lambdoid suture.

In the facial bones, neither zygomatic nor sphenoid bones showed signs of pathological changes. However, the nasal bones were particularly affected. On the left side, post mortem destruction obscured the original appearance, whereas the nasal bone on the right side was clearly destroyed before death, making the nasal opening higher than normal (Fig. 1A). The development of a new layer of bone was clearly observed in both wings of the vomer. On the right maxilla, the cortex lateral to the nasal aperture showed extended fine pitting. The right margin of the inferior half of the piriform aperture was slightly thicker and more remodelled than the unaffected left margin. No pathological changes were visible inside the nasal cavity.

Examination of the endocranium, using a lighted probe, revealed evidence of pitting on the frontal and parietal bones that was most severe at the level of the metopic suture; findings also included a small radial 
scar on the right parietal bone. The locations of these endocranial lesions were clearly correlated with areas of particularly severe ectocranial destruction.

With regard to the dentition, the skull showed only 28 alveoli and seven teeth were lost from the maxilla post mortem. The first right molar was missing ante mortem and in the lateral aspect of the maxilla, the alveolar bone showed signs of new bone formation. All six remaining maxillary teeth showed calculus and the second right molar had a carious lesion on the occlusal surface. At the level of the apex of the right canine socket, there was a small perforating lesion with a sharp irregular margin that corresponded to a periapical cyst according to the description by Dias et al. (2007). In the mandible, 10 teeth were lost post mortem, leaving only the right and left first and second molars. Except for calculus, none of these teeth showed any pathology. There was an area of new bone formation in the lateral aspect of the right mandibular ramus, particularly near the superior margin; below, there was also some porosity on the medial aspect of the ramus.

Acquired syphilis and other forms of treponematosis, such as yaws and endemic syphilis, can produce cranial caries sicca (Ortner 2003, Powell \& Cook 2005). However, according to the available data for this individual, it is very unlikely that this woman could have suffered from yaws or endemic syphilis. After all, the appearance of the cranial lesions suggests that she suffered from one of the treponemal diseases, most probably acquired syphilis.

According to the above findings, one of the most interesting issues regarding individual 282 is to what extent the paleopathological diagnosis and the recorded cause of death could be related. This inquiry implies that the liver may play a role in the pathogenesis of syphilis. Cirrhosis is a condition in which the liver slowly deteriorates and malfunctions due to chronic injury. Cirrhosis partially blocks the flow of blood and prevents the liver from performing its normal functions, including controlling infections, removing bacteria and toxins from the blood and processing nutrients, hormones and drugs (NDDIC 2008). According to Wolf (2007), the progression from liver injury to cirrhosis may occur over a period of weeks or years. Despite the fact that alcoholic liver disease was once considered to be the predominant cause of cirrhosis (Wolf 2007), many other diseases, including syphilis, can lead to that condition (Rebocho 1921, Heidelbaugh \& Bruderly 2006). In 1984, Terry et al. (1984) verified that patients with secondary syphilis showed unhealthy livers. According to other authors, cirrhosis is a frequent manifestation of the tertiary stage of the disease (Monteiro 1915, Rebocho 1921, Pareek 1979) and develops in patients between 30-50 years of age (Monteiro 1915).

Another relatively common cause of injury to the liver is the administration of drugs, such as mercury compounds that were used to treat acquired syphilis (Quétel 1990, Hall 2001) and were prescribed in Portugal (Quétel 1990, Ortner 2003, Souza et al. 2006). However, the effectiveness of mercury is still a mat- ter of debate (Tucker 2007). Mercury ointments promote healing of skin lesions and therefore appear to halt the progression of acquired syphilis; however, like many other attempted cures, this treatment was often as dangerous as the disease itself, if not more so (Quétel 1990, Hall 2001). Ortner (2003) believed that many of the XIX century European syphilis cases with exuberant bone lesions reflect treatment with mercury. In contrast, Tucker (2007) reported that syphilitic bone lesions were less severe in individuals who received this treatment. The effect of mercury, a highly toxic metal, on the body could be devastating with a large number of side effects, including gastro-enteritis, diarrhoea, vomiting (Faro 1919), cutaneous eruptions, neurological effects (Quétel 1990) and irreparable damage to the kidneys and liver (Faro 1919), which could potentially result in severe cirrhosis. The liver is a major organ for mercury metabolism and accumulation; these processes could result in severe haepatic damage regardless of the method of administration (Wadaan 2009).

Medication with mercury may also produce several types of damage to the teeth (Powell \& Cook 2005, Souza et al. 2006), including gingivitis, that result in the loss of dentition (Quétel 1990), abrasions and discoloration of the tooth enamel (Souza et al. 2006). The loss of 18 teeth in this relatively young individual makes it difficult to evaluate the possible changes in the surface of the teeth that may have been related to treatment with mercury. However, in the 10 teeth that were present, there were no specific signs of mercury use.

The life story of individual 282 who died in 1899 is poorly understood. This woman lived and died several decades before the development of penicillin and we do not know whether she received any kind of medical assistance or treatment. Syphilis patients today may survive decades without treatment (de Melo et al. 2010). Tertiary stage symptoms, such as caries sicca, do not typically appear until at least a decade after the initial infection, but some patients progress more rapidly to the final stage of the disease (Chulay 1990). Because this woman died at the age of 28 , she probably was infected during adolescence.

During her lifetime, modern diagnostic methods such as the Wasserman test were unknown; therefore, her tertiary stage lesions may not have been associated with an episode of the disease that occurred many years before. Could this also explain why such an advanced stage of syphilis was omitted from the certificate of death? Another hypothesis is that syphilis was not mentioned as the cause of death because of the negative social stigma attached to this venereal disease, although the extent of the lesions on the skull of this young woman suggests that signs of infection would have been quite visible unless they were deliberately and carefully concealed. Furthermore, she may have also suffered from other diseases that caused the fatal "hypertrophic cirrhosis of the liver". It is impossible to state if her cirrhosis had an alcoholic aetiology. However, it is known that alcoholism was a very serious problem in late XIX century Portuguese society; she may have been a victim of both syphilis and alcoholism. 
In this study, sources of clinical medicine, medical history and paleopathology were combined to explore the possible associations between the stated cause of her death and the unmistakable bony scars of a deadly infectious disease (syphilis). From her biographic information, we can concluded that she migrated from a small town in the provinces to the big city, presumably to find work as a housemaid, and she died while suffering from a disease that exacted a terrible toll at the end of the XIX century.

\section{ACKNOWLEDGEMENTS}

To Museum of Anthropology at University of Coimbra, Della Collins Cook, Vítor Matos and two anonymous reviewers.

\section{REFERENCES}

Aufderheide AC, Rodríguez-Martín C 1998. The Cambridge encyclopedia of human paleopathology, Cambridge University Press, Cambridge, 478 pp.

Chulay JD 1990. Treponema species (yaws, pinta, bejel). In GL Mandell, R Douglas, JE Bennett (eds.), Principles and practice of infectious diseases, Churchill and Livingstone, New York and London, p. 1808-1812.

Davidson R, Hall LA 2001. Sex, sin and suffering. Venereal disease and European society since 1870, Routledge, London and New York, $259 \mathrm{pp}$.

de Melo FL, de Mello JC, Fraga AM, Nunes K, Eggers S 2010. Syphilis at the crossroad of phylogenetics and paleopathology. PLoS Negl Trop Dis 4: e575.

Dias GJ, Prasad K, Santos AL 2007. Pathogenesis of apical periodontal cysts: guidelines for diagnosis in palaeopathology. Int $\mathrm{J} O s$ teoarchaeol 17: 619-626.

Faro EM 1919. Contribuição para o estudo do tratamento da sifilis. Vantagem da associação arseno-mercurial, University of Coimbra, Coimbra, 88 pp.

Guimarães P 1897. O tratamento da syphilis pelo método das injecções hypodermicas insolúveis, Escola Médico-Cirúrgica do Porto, Porto, $73 \mathrm{pp}$.

Hackett CJ 1976. Diagnostic criteria of syphilis, yaws and treponarid (treponematoses) and of some other diseases in dry bones, Springer-Verlag, Berlin, $467 \mathrm{pp}$.

Hall L 2001. Venereal diseases and society in Britain, from the contagious diseases acts to the National Health Service. In R Davidson, LA Hall, Sex, sin and suffering. Venereal disease and European society since 1870, Routledge, London and New York, p. 120-136.

Heidelbaugh JJ, Bruderly M 2006. Cirrhosis and chronic liver failure: part I. Diagnosis and evaluation. Am Fam Physician 74: 756-762.
Marden K, Ortner DJ 2009. A case of treponematosis from Pre-Columbian Chaco Canyon, New Mexico. Int J Osteoarchaeol 2009 oct [cited 2010, March 30]: [about 13 p.]. Available from: www3. interscience.wiley.com/cgi-bin/fulltext/122652112/PDFSTART.

Monteiro HB 1915. Sifilis hepática, University of Porto, Porto, 165 pp.

Musher DM 1999. Early syphilis. In K Holmes, PA Mårdh, P Sparling, S Lemon, W Stamm, P Piot, J Wasserheit, Sexually transmitted diseases, McGraw-Hill, New York, p. 479-485.

NDDIC - The National Digestive Diseases Information Clearinghouse [homepage on the Internet]. Cirrhosis. [updated December 2008; cited 2010 June 14]. Available from: http://digestive.niddk. nih.gov/ddiseases/pubs/cirrhosis/.

Ortner D 2003. Identification of pathological conditions in human skeletal remains, Academic Press, London, 645 pp.

Pareek SS 1979. Liver involvement in secondary syphilis. Dig Dis Sci 24: 41-43.

Peeters L, Van Vaerenbergh W, Van der Perre C, Lagrange W, Verbeke M 2005. Tertiary syphilis presenting as hepatic bull's eye lesions. Acta Gastroenterol Belg 68: 435-439.

Powell ML, Cook DC 2005. The myth of syphilis: the natural history of treponematosis in North America, University Press of Florida, Gainesville, 509 pp.

Quétel C 1990. History of syphilis, Johns Hopkins University Press, Maryland, $342 \mathrm{pp}$.

Rebocho E 1921. A sifilis obscura, University of Coimbra, Coimbra, $36 \mathrm{pp}$.

Souza SM, Codinha S, Cunha E 2006. The girl from the Church of the Sacrament: a case of congenital syphilis in XVIII century Lisbon. Mem Inst Oswaldo Cruz 101 (Suppl. II): 119-128.

Terry SI, Hanchard B, Brooks SE, McDonald H, Siva S 1984. Prevalence of liver abnormality in early syphilis. Br J Vener Dis 60: 83-86.

Tucker F 2007. Kill or cure? The osteological evidence of the mercury treatment of syphilis in 17th to 19th-century London. Lond Archaeol SPRING 11: 220-224.

Vaquinhas IM 1992. O conceito de "decadência fisiológica da raça" e o desenvolvimento do desporto em Portugal (finais do século XIX/princípios do século XX). Rev Hist Ideias 14: 365-388.

Wadaan MAM 2009. Effects of mercury exposure on blood chemistry and liver histopathology of male rats. J Pharmacol Toxicol 4: $126-131$.

Wöhrl S, Geusau A 2007. Clinical update: syphilis in adults. Lancet 369: 1912-1914.

Wolf DC 2007. Cirrhosis. Emedicine [serial on the internet], Feb 14, 2007 [cited July, 31, 2008]; Available from: http://www.emedicine.com/med/TOPIC3183.HTM. 